\title{
Genome-Wide Association Study Points New Direction for Downbeat Nystagmus Research
}

\author{
Aasef G. Shaikh ${ }^{1,2,3,4,5} \cdot$ Mario Manto ${ }^{6,7}$ \\ Published online: 6 April 2020 \\ (C) Springer Science+Business Media, LLC, part of Springer Nature 2020
}

The oscillations of the eyes present in one form or the other invariably have devastating consequences on the quality of life. The nystagmus, when jerky and in the horizontal direction, causes sense of spinning; when pendular, the patients feel as if the environment is shaking. The eye oscillations in the vertical direction often give an illusion that the visual surround is tilting forward or backward causing (actual) compensation of (illusory) tilt leading to fall. A simple classification with characteristics of typical nystagmus is depicted in Table 1. Among many causes, eye oscillations are often caused by the central nervous system disorders. Vertical nystagmus is one of the classic presentations of the lesions affecting the structures of posterior fossa of the skull. One of the most common forms of nystagmus, downbeat nystagmus (DBN), either part of a known syndromic entity or isolated, is a frequent cause of fall in patients with cerebellar deficits. The entity was described by Dr. David Cogan in the mid-1960s [1]. DBN is the second most common form of nystagmus published according to PubMed citations, gaze-evoked nystagmus being the most common form. Although frequently

Aasef G. Shaikh

aasefshaikh@gmail.com

1 Neurological Institute, University Hospitals Cleveland, Cleveland, OH, USA

2 Department of Neurology, Case Western Reserve University, Cleveland, $\mathrm{OH}$, USA

3 Department of Biomedical Engineering, Case Western Reserve University, Cleveland, OH, USA

4 Neurology Service and Daroff-Dell'Osso Ocular Motility Laboratory, Louis Stokes Cleveland Medical Center, Cleveland, OH, USA

5 Department of Neurology, University Hospitals Cleveland Medical Center, 11100 Euclid Avenue, Cleveland, OH 44110, USA

6 Department of Neurology, CHU-Charleroi, Charleroi, Belgium

7 University of Mons, Mons, Belgium published, the cause of DBN remains unknown in $65 \%$ of instances (Fig. 1). A comprehensive single-center study of the large number of patients with vertigo and dizziness revealed that 369 out of 2000 patients were dizzy without having any structural deficits. Among these patients, $24 \%$ had central nystagmus; idiopathic DBN was present in $64 \%$ of those with central nystagmus [2]. The most common diagnosis in patients with central vertigo in the absence of structural deficits was idiopathic cerebellar ataxia; $25 \%$ had idiopathic $\mathrm{DBN}$, making this phenomenology the second most common cause of central vertigo and dizziness in the absence of any structural etiology [2]. The remaining question is what causes the idiopathic DBN.

The idiopathic nature of DBN is frustrating to the sufferers, caregivers, and researchers. Despite numerous therapies, the success remains often unpredictable and incomplete. A recent study published in this volume of the Cerebellum has shed light towards better understanding of the "idiopathic" DBN [3]. A genome-wide association study of 106 patients of European ancestry identified genetic variants. One of the most common variants was on chromosome 13 located within the fibroblast growth factor 14 (FGF14) gene, a gene heavily expressed in the cerebellar Purkinje neurons, the sole output of the cerebellar cortex circuitry [3]. Reduction of the FGF14 is known to cause decreased spontaneous firing and excitability of the Purkinje neurons via its role in modulating voltagegated ion channels [4-8]. The correlation of FGF14 gene with $\mathrm{DBN}$ is in synchrony with the gene's influence on the cellular physiology and association with voltage-gated ion channels that are also targets for successful pharmacotherapeutic agents for this the condition. For example, aminopyridines that are known to treat DBN also seem to utilize voltage-gated ion channels for their mechanism of action [9].

The FGF14 gene is also implicated in spinocerebellar ataxia type 27 (SCA27). The common association of FGF14 with DBN and SCA27 poses a key question: what is the phenotypic similarity between isolated DBN and those with spinocerebellar ataxia type 27 ? The latter, a typical childhood 
Table 1 Simple classification of nystagmus subtypes

Nystagmus

\begin{tabular}{|c|c|c|c|c|c|c|}
\hline \multicolumn{6}{|c|}{ Jerk (slow drifts followed by corrective beats) } & \multirow{2}{*}{$\begin{array}{l}\text { Pendular } \\
\text { (sinusoidal } \\
\text { oscillations) }\end{array}$} \\
\hline Hori & ntal & & & Torsional & Mixed & \\
\hline $\begin{array}{c}\text { Gaze-evoked } \\
\text { (extreme } \\
\text { peripheries) }\end{array}$ & $\begin{array}{l}\text { Spontaneous } \\
\text { (straight } \\
\text { gaze) }\end{array}$ & $\begin{array}{l}\text { Downbeat } \\
\text { (straight \& } \\
\text { downgaze) }\end{array}$ & $\begin{array}{l}\text { Upbeat } \\
\text { (straight \& } \\
\text { upgaze) }\end{array}$ & & $\begin{array}{l}\text { See-saw } \\
\text { (torsional \& } \\
\text { vertical) }\end{array}$ & \\
\hline
\end{tabular}

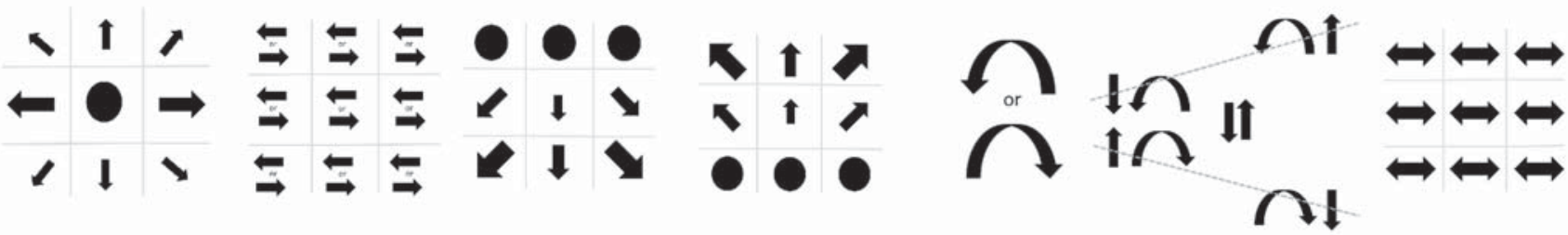

Aarrow size: intensity of nystagmus

Arrow direction: direction of nystagmus.

Circle: stable gaze

onset disorder, presents with tremor, robust gait ataxia, depression, and anger outbursts [10-14]. Nystagmus is reported in about $84 \%$ of spinocerebellar ataxia patients, but DBN is extremely rare and was reported only twice in the literature [12]. Parkinsonism is another feature of spinocerebellar ataxia type 27 [12].

Given genetic relationship between SCA27 and DBN, is it possible that the two depict variable expression of the same genotype? Penetrance is another possibility, that is, "idiopathic" DBN is a late-onset and mild manifestation of the SCA27. Indeed, DBN is known to present with essential tremor of the

\section{Literature reporting the etiologies of downbeat nystagmus}

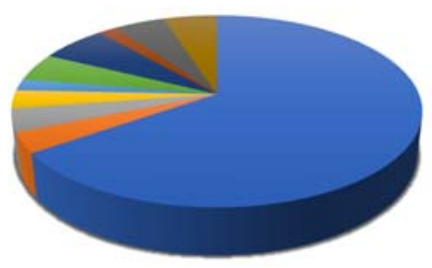

=Idiopathic
$\equiv$ Stroke
$=$ Drug-induced
$=$ Demyelination
$=$ Infection
$=$ Degeneration
$=$ Episodic ataxia
$=$ Part of genetic syndrome
$=$ Tumor/Mass
$=$ Chiari malformation

Fig. 1 Chart depicts frequency of published literature on downbeat nystagmus. PubMed search criteria for all forms of downbeat nystagmus using a key search "downbeat nystagmus". Literature on the downbeat nystagmus with stroke was searched on PubMed with key terms "downbeat nystagmus and stroke." Same strategy was utilized to search studies reporting other (known) etiologies of downbeat nystagmus. A total of all etiologies were calculated and subtracted from the number for all downbeat nystagmus to find those with "idiopathic" downbeat nystagmus. The figure depicts that there are many causes of downbeat nystagmus but idiopathic is one of the most common forms, noted in $65 \%$ of the literature cited in PubMed arm and head; such features are thought to be "variant of essential tremor" or "suggest the cerebellar etiology of essential tremor" [15]. Gait ataxia is now considered a feature in patients with essential tremor. Therefore, one might argue that DBN along with essential tremor may manifest in adult onset mild form of SCA27. While prevalence of FGF14 mutation is unknown in patients with DBN and essential tremor, future investigations examining this possibility are welcome.

FGF14 mutation in SCA27 is also associated with depression and anger outbursts. While depression and anxiety are frequently seen in chronic neurological conditions, the biological relationship and increased co-prevalence between depression and idiopathic DBN remain unknown. Parkinsonism also co-occurred with SCA27. While patients with isolated DBN do not typically manifest signs of parkinsonism, clinicians often consider the diagnosis of "multiple system atrophy" when DBN (and additional cerebellar signs) is associated with parkinsonism.

Although FGF14 on chromosome 13 remained genomewide significant, there were additional suggestive associations for 15 linkage disequilibrium independent regions. The promising ones were localized to chromosome $5 q 14.1$ where the two overlapping genes DHFR and MSH3 are found [3]. DHFR, an important enzyme in folate metabolism, influences basic cellular processes leading to regulation of genes and production of amino acids, nucleic acids, and neurotransmitters as well as preventing neurotoxicity and degeneration [16, 17]. MSH3 influences cell cycle regulation, apoptosis, and genome stability [18]. Altogether, one could interpret that 
three relevant associations found in genome-wide analysis in DBN patients have distinct biological consequences. Such differences in biology could provide the mechanistic understanding for the differences in the pharmacotherapeutic success. For example, it is plausible that in patients where ion channels are involved in pathogenesis, such as FGF14, the pharmacological modulation with aminopyridines or other compounds have meaningful influence on the patients' symptoms. On the contrary, in patients where the deficits are in gene, neurotransmitter, or protein regulation, the subjects are relatively refractory to pharmacotherapy.

The genome-wide association study of DBN patients provides novel and highly valuable information, some of which help us to understand molecular understanding of the common disease affecting the eye movements. In the settings of complex and heterogeneous disorders such as cerebellar ataxias for whom genetics play a key role in pathogenesis, this is particularly relevant. At the same time, the results have also lead to several important questions opening up the stage for future investigations.

\section{References}

1. Cogan DG. Down-beat nystagmus. Arch Ophthalmol. 1968;80: 757-68. https://doi.org/10.1001/archopht.1968.00980050759015.

2. Feil K, Strobl R, Schindler A, Krafczyk S, Goldschagg N, Frenzel $\mathrm{C}$, et al. What is behind cerebellar vertigo and dizziness? Cerebellum. 2019;18:320-32. https://doi.org/10.1007/s12311018-0992-8.

3. Strupp M, Maul S, Konte B, Hartmann AM, Giegling I, Wollenteit $\mathrm{S}$, et al. Variation in FGF14 is associated with downbeat nystagmus in a genome-wide association study. Cerebellum. 2020; (in press).

4. Pablo JL, Pitt GS. FGF14 is a regulator of KCNQ2/3 channels. Proc Natl Acad Sci U S A. 2017;114:154-9. https://doi.org/10.1073/ pnas.1610158114.

5. Yan H, Pablo JL, Pitt GS. FGF14 regulates presynaptic Ca2+ channels and synaptic transmission. Cell Rep. 2013;4:66-75. https://doi. org/10.1016/j.celrep.2013.06.012.

6. Shakkottai VG, Xiao M, Xu L, Wong M, Nerbonne JM, Ornitz $\mathrm{DM}$, et al. FGF14 regulates the intrinsic excitability of cerebellar Purkinje neurons. Neurobiol Dis. 2009;33:81-8. https://doi.org/10. 1016/j.nbd.2008.09.019.

7. Bosch MK, Carrasquillo Y, Ransdell JL, Kanakamedala A, Ornitz DM, Nerbonne JM. Intracellular FGF14 (iFGF14) is required for spontaneous and evoked firing in cerebellar Purkinje neurons and for motor coordination and balance. J Neurosci. 2015;35:6752-69. https://doi.org/10.1523/JNEUROSCI.2663-14.2015.

8. Xiao M, Bosch MK, Nerbonne JM, Ornitz DM. FGF14 localization and organization of the axon initial segment. Mol Cell Neurosci. 2013;56:393-403. https://doi.org/10.1016/j.mcn.2013.07.008.

9. Strupp M, Kalla R, Dichgans M, Freilinger T, Glasauer S, Brandt T. Treatment of episodic ataxia type 2 with the potassium channel blocker 4-aminopyridine. Neurology. 2004;62:1623-5. https://doi. org/10.1212/01.wnl.0000125691.74109.53.

10. Brusse E, de Koning I, Maat-Kievit A, Oostra BA, Heutink P, van Swieten JC. Spinocerebellar ataxia associated with a mutation in the fibroblast growth factor 14 gene (SCA27): a new phenotype. Mov Disord. 2006;21:396-401. https://doi.org/10.1002/mds.20708.

11. Chen Z, Li X, Tang B, Wang J, Shi Y, Sun Z, et al. Spinocerebellar ataxia type 27 (SCA27) is an uncommon cause of dominant ataxia among Chinese Han population. Neurosci Lett. 2012;520:16-9. https://doi.org/10.1016/j.neulet.2012.05.008.

12. Groth CL, Berman BD. Spinocerebellar ataxia 27: a review and characterization of an evolving phenotype. Tremor Other Hyperkinet Mov (N Y). 2018;8:534. https://doi.org/10.7916/ D80S0ZJQ.

13. Misceo D, Fannemel M, Baroy T, Roberto R, Tvedt B, Jaeger T, et al. SCA27 caused by a chromosome translocation: further delineation of the phenotype. Neurogenetics. 2009;10:371-4. https://doi. org/10.1007/s10048-009-0197-x.

14. Shimojima K, Okumura A, Natsume J, Aiba K, Kurahashi H, Kubota T, et al. Spinocerebellar ataxias type 27 derived from a disruption of the fibroblast growth factor 14 gene with mimicking phenotype of paroxysmal non-kinesigenic dyskinesia. Brain and Development. 2012;34:230-3. https://doi.org/10.1016/j.braindev. 2011.04.014.

15. Kim YE, Kim JS, Yang HJ, Yun JY, Kim HJ, Ehm G, et al. Perverted head-shaking and positional downbeat nystagmus in essential tremor. Cerebellum. 2016;15:152-8. https://doi.org/10. 1007/s12311-015-0683-7.

16. Iskandar BJ, Nelson A, Resnick D, Skene JH, Gao P, Johnson C, et al. Folic acid supplementation enhances repair of the adult central nervous system. Ann Neurol. 2004;56:221-7. https://doi.org/10. 1002/ana.20174.

17. Iskandar BJ, Rizk E, Meier B, Hariharan N, Bottiglieri T, Finnell $\mathrm{RH}$, et al. Folate regulation of axonal regeneration in the rodent central nervous system through DNA methylation. J Clin Invest. 2010;120:1603-16. https://doi.org/10.1172/JCI40000.

18. Palombo F, Iaccarino I, Nakajima E, Ikejima M, Shimada T, Jiricny J. hMutSbeta, a heterodimer of hMSH2 and hMSH3, binds to insertion/deletion loops in DNA. Curr Biol. 1996;6:1181-4. https://doi.org/10.1016/s0960-9822(02)70685-4.

Publisher's Note Springer Nature remains neutral with regard to jurisdictional claims in published maps and institutional affiliations. 